\title{
Kajian Implementasi Kesehatan dan Keselamatan Kerja Dengan Pendekatan Behavior Based Safety
}

\author{
Fitri Agustina ${ }^{1}$, Nachnul Ansori ${ }^{2}$, Trisita Novianti ${ }^{3}$, Miftakhul Farikha $^{4}$
}

\begin{abstract}
This study discusses about how to evaluate the implementation of occupational health and safety (OHS) on batik small and medium sized enterprises in Madura. Successful implementation of OHS is influenced by worker behavior and then is measured by a score of worker safety through the intervention program. Intervention program is designed by using behavior-based safety approach that is based on the identification of hazards and risks at workplace. Intervention program is conducted by the provision of personal protective equipment, work standard setting, supervision and understanding improvement of the OHS. The results show that interventions can improve worker safety score from $34 \%$ to $56 \%$
\end{abstract}

Keywords. Behavior based safety, safe score, OHS, intervention, batik Madura

\begin{abstract}
Abstrak. Artikel ini membahas tentang kajian evaluasi implementasi kesehatan dan keselamatan kerja (K3) pada industry kecil menengah batik tulis di Madura. Keberhasilan implementasi K3 dipengaruhi salah satunya oleh perilaku kerja pekerja dan kemudian diukur dengan skor keselamatan pekerja melalui program intervensi. Program intervensi dirancang dengan pendekatan behavior based safety yang didasarkan pada identifikasi bahaya dan resiko di tempat kerja. Program intervensi dilakukan dengan penyediaan alat pelindung diri, menetapkan standar kerja, meningkatkan pengawasan dan pemahaman pekerja tentang K3. Hasil penelitian menunjukkan bahwa intervensi yang dilakukan dapat meningkatkan skor keselamatan pekerja dari $34 \%$ menjadi $56 \%$.
\end{abstract}

Kata kunci. behavior based safety, safe score, K3, intervensi, batik Madura

\section{PENDAhUluan}

Di Indonesia terdapat beragam jenis batik yang memiliki keunikan sesuai daerah atau pun provinsi dimana batik tersebut dihasilkan. Muhimatul, dkk (2013) menyebutkan, bahwa batik Madura menjadi salah satu produk unggulan yang potensial untuk dikembangkan.

\footnotetext{
${ }^{1}$ Fitri Agustina, Prodi Teknik Industri, Fakultas Teknik, Universitas Trunojoyo, J1. Raya Telang PO BOX 2 Kamal, Bangkalan (email: fitri_agustina@trunojoyo.ac.id)

${ }^{2}$ Nachnul Ansori, Prodi Teknik Industri, Fakultas Teknik, Universitas Trunojoyo, Jl. Raya Telang PO BOX 2 Kamal, Bangkalan (email: nachnul@gmail.com)

3 Trisita Novianti, Prodi Teknik Industri, Fakultas Teknik, UniversitasTrunojoyo, Jl. Raya Telang PO BOX 2 Kamal, Bangkalan (email: trisitanovianti@trunojoyo.ac.id)

${ }^{4}$ Miftakhul Farikha, Prodi Teknik Industri, Fakultas Teknik, Universitas Trunojoyo, Jl. Raya Telang PO BOX 2 Kamal, Bangkalan (email: miftakhulfarikhah@gmail.com)
}

Diajukan: 14-10-2016

Diperbaiki: 1-12-2016
Industri batik termasuk ke dalam industry tekstil atau resource based industries yang berarti bahwa kompetensi industri lebih banyak ditentukan oleh potensi sumber daya (resource) yang dibutuhkan dalam proses industri, terutama bahan baku yang berasal dari sumber daya alam dan sumber daya manusia lokal.

Industri batik yang merupakan industry prioritas, memiliki wilayah pengembangan di Bangkalan, Sampang, Pamekasan dan Sumenep. Namun sentra yang terbesar berada di kabupaten Bangkalan dan Pamekasan telah menjadi pusat pengembangan kawasan industry kecil dan kerajinan rakyat yang memiliki reputasi nasional.

Di Madura, industri batik didominasi oleh industry skala kecil dan menengah (IKM), dimana standar kerja banyak yang belum terpenuhi. Menurut Xiongjun dan Kaiqan (2012), tidak terpenuhinya standar dalam bekerja tersebut cukup banyak berkaitan dengan riwayat pendidikan. Dimana pengrajin batik tulis sebagian besar berpendidikan akhir setingkat sekolah menengah dan atas. Salah satu standar kinerja yang belum ada adalah pada pelaksanaan kesehatan dan keselamatan kerja dikarenakan 
tidak adanya jaminan kesehatan maupun kompensasi kecelakaan ataupun sakit akibat kerja disebabkan perusahaan tidak terdaftar secara resmi. Rendahnya kepedulian, kesadaran, serta pengetahuan mengenai potensi bahaya di lingkungan dan fasilitas kerja juga menjadi penyebab belum tercapainya standar dari kesehatan dan keselamatan kerja di UKM Batik di Madura.

Berdasarkan simpulan yang dinyatakan oleh Al-Hemoud dan Al-Asfoor (2006), bahwa unsafe acts merupakan penyebab terbesar dari kecelakaan kerja terbanyak sebesar $88 \%$ dari total penyebab masalah keselamatan kerja, kemudian diikuti oleh unsafe conditions sebanyak $10 \%$, dan sisanya $2 \%$ merupakan penyebab yang tidak dapat dicegah ataupun dihindari. Oleh karena itu akan lebih baik jika perusahaan sadar akan pentingnya penanganan perilaku aman, karena tingkat kecelakaan dapat menurun sebanyak $40 \%$ hingga $70 \%$ dalam waktu $12-16$ bulan jika teknik behavioral safety mampu diterapkan (Wignjosoebroto, 2012).

Pada pelaksanaan produksinya, pengrajin batik banyak mempertimbangkan factor keuntungan semata, namun seringkali mengabaikan resiko bahaya yang dihadapi. Meningkatnya jumlah permintaan batik dari waktu ke waktu dan semakin ketatnya tingkat persaingan menyebabkan pengrajin dituntut untuk memenuhi permintaan tersebut dalam waktu yang cepat serta ongkos produksi yang murah. Salah satu komponen ongkos produksi adalah penggunaan zat warna tekstil. Hampir semua pengrajin batik di Madura menggunakan pewarna sintetis/kimia daripada pewarna alami untuk menekan ongkos produksi. Namun, penggunaan jenis pewarna tersebut dalam produksi batik tidak dibarengi dengan adanya pengelolahan limbah batik yang aman.

Perilaku penanganan limbah secara sembarang tersebut didasari oleh ketidak pedulian pengrajin batik akibat tidak tersedianya wadah penampung untuk pengelolaan limbah batik. Selain itu juga tidak adanya perhatian dari pemerintah sekitar akan kelangsungan lingkungan hidup sekitar pemukiman. Hal tersebut memicu ketidakpedulian pengrajin batik secara terusmenerus acuh terhadap potensi resiko bahaya yang ada. Hal ini sesuai dengan hasil penelitian yang dilakukan oleh Ansori, dkk. (2015), bahwa terdapat tiga faktor yang mempengaruhi perilaku kerja tidak aman pada bagian pewarnaan, yaitu penanganan limbah, alat pelindung diri (APD), pengetahuan dan pengalaman. Sehingga pada penelitian ini bertujuan untuk melakukan rancangan untuk mengurangi tingkat perilaku tidak aman tersebut berdasarkan factor penanganan limbah serta pengetahuan dan pengalaman.

Behavior Based Safety (BBS) merupakan metode pendekatan yang paling sesuai untuk unsafe behaviors dengan pertimbangan mampumeningkatkan manajemen keselamatan serta mencegah terjadinya kecelakaan (Xiongjun \& Kaiqan, 2012). Metode ini bertujuan untuk mengurangi tingkat resiko yang disebabkan oleh perilaku dari manusia dan mengembangkan fungsi dari perilaku aman, memperbaiki perilaku bahaya, mengenalkan lingkungan aman dan mengembangkan kinerja aman. Pada penelitian ini dilakukan intervensi untuk mengurangi resiko akibat perilaku tidak aman dengan menggunakan BBS.

\section{Metodologi}

Penelitian ini tergolong kedalam applied research yang bertujuan untuk mengaplikasikan hasil penelitian terdahulu sebagai bentuk tindak lanjut yang bersifat sistematis serta untuk diuji dan evaluasi pada saat diimplementasikan.

Variabel K3 yang akan digunakan dalam penelitian ini didasarkan dari hasil observasi lapangan dan didukung oleh Ansori, dkk (2015) yang menyatakan bahwa terdapat tujuh faktor yang berpengaruh terhadap perilaku tidak aman pada proses pembatikan yaitu penanganan limbah, pengetahuan dan pengalaman, alat pelindung diri, kondisi kerja, pengawasan, serta pengetahuan dan pengalaman.

Pengamatan perilaku kerja dilakukan dengan mengidentifikasi bahaya serta evaluasi resiko dengan menggunakan pendekatan semi kuantitatif untuk menghitung level of rating. Dengan menggunakan formulasi Fine (1971) menyatakan:

$$
R=C x E x P
$$

dimana: $R=$ level of rating, $C=$ consequences, $E=$ Exposure, dan $P=$ Probability.

Pada pengukuran safe score akan digunakan kuisioner CBC (critical behavior checklist) yaitu pada sebelum dan setelah intervensi. Formulasi perhitungan \% safe score yang dinyatakan oleh 
Williams danGeller (2000) adalah sebagai berikut:

$\%$ safe scores $=\frac{T S O}{T S O+T R O} \times 100 \%$

dimana, TSO = total save observation, dan $T R O=$ total at-risk obsenvation.

Dalam melakukan pendekatan Behavior Based Safety (BBS) terdapat beberapa langkah yang dilakukan sesuai penjelasan Dula dan Geller (2007) sebagai berikut :

1. Define (D), dimana pada tahap pertamaini dilakukan penentuan target perilaku yang terbagi menjadi safe untuk perilaku aman dan at-risk untuk perilaku bahaya.

2. Observing $(\mathrm{O})$, dimana pada tahap kedua ini dilakukan pengamatan terhadap perilaku yang dituju dalam rentang waktu tertentu untuk mengidentifikasi faktor lingkungan dan sosial yang berpengaruh terhadap perilaku sekaligus direkam untuk penentuan tujuan, serta pengumpulan evaluasi data intervensi.

3. Intervening (I), dimana tahap ketiga pada langkah ini adalah intervensi berdasarkan perencanaan BBS.

4. Testing ( $\mathrm{T})$, dimana setelah tiga langkah sebelumnya telah terpenuhi, selanjutnyaadalah pengujian efektivitas intervensi dengan cara pengamatan berkelanjutan dan merekam bagaimana perilaku yang terjadi. Langkah terakhir ini dilakukan dengan menggunakan CBC (Critical Behavior Checklist).

\section{HASIL DAN PEMBAHASAN}

Pada penelitian ini terdapat subjek penelitian sebanyak 9 orang. Adapun karakterisik subjek penelitian ini diringkas dalam Tabel 1.

Tabel 1. Karakteristik subyek penelitian

\begin{tabular}{lccc}
\hline Karakteristik subyek & Mean & Modus & Range \\
\hline Umur (tahun) & 28 & 30 & $19-45$ \\
Masa kerja (tahun) & 7,67 & 5 & $3-16$ \\
Pendidikan & \multicolumn{3}{c}{ SD - SMP } \\
Jenis kelamin & \multicolumn{3}{c}{ Perempuan } \\
\hline
\end{tabular}

Menurut Geller dalam Wayne (2004), inti dari program BBS adalah proses pendefinisian 1) Target perilaku, 2) Pengamatan target perilaku, 3) Pelaksanaan intervensi untuk meningkatkan perilaku, 4) Pengujian hasil intervensi. proses tersebut biasa disebut dengan DOIT (Defining, Observing, Intervening, Testing). Adapun dalam penelitian ini langkah pertama sebagai bentuk defining dilakukan dengan melakukan identifikasi bahaya dan analisis resiko pada Tabel 2 sesuai dengan metode semi kuantitatif yang disampaikan

Tabel 2. Identifikasi bahaya dan resiko pada produksi batik

\begin{tabular}{|c|c|c|c|c|c|}
\hline Process & Hazard & Exposure & Deviation & Consequences & Caused \\
\hline Pembatikan & $\begin{array}{l}\text { Panas, uap } \\
\text { malam, } \\
\text { malam } \\
\text { panas }\end{array}$ & Continously & $\begin{array}{l}\text { Pekerja tidak } \\
\text { menggunakan } \\
\text { masker dan } \\
\text { sarung tangan }\end{array}$ & $\begin{array}{l}\text { Tangan melepuh } \\
\text { akibat kontak } \\
\text { dengan malam } \\
\text { panas/peralatan. } \\
\text { Paparan uap malam } \\
\text { terhirup }\end{array}$ & $\begin{array}{l}\text { Tidak tersedia alat } \\
\text { pelindung diri }\end{array}$ \\
\hline Pewarnaan & $\begin{array}{l}\text { Zat warna, } \\
\text { lantai licin }\end{array}$ & Occasionally & $\begin{array}{l}\text { Pekerja tidak } \\
\text { memakai sarung }\end{array}$ & $\begin{array}{l}\text { Paparan zat warna } \\
\text { textile terhirup. }\end{array}$ & $\begin{array}{l}\text { Tidak tersedia alat } \\
\text { pelindung diri }\end{array}$ \\
\hline Pelorodan & $\begin{array}{l}\text { Air panas, } \\
\text { malam, } \\
\text { lantai licin, } \\
\text { zat warna }\end{array}$ & & $\begin{array}{l}\text { tangan, masker } \\
\text { dan safety shoes }\end{array}$ & $\begin{array}{l}\text { Tangan dan kaki } \\
\text { terpapar zat warna } \\
\text { Iritasi kulit } \\
\text { Kaki kontak dengan } \\
\text { ceceran zat warna } \\
\text { Terpeleset }\end{array}$ & $\begin{array}{l}\text { berupa masker, } \\
\text { sarung tangan dan } \\
\text { safetyshoes }\end{array}$ \\
\hline $\begin{array}{l}\text { Penanganan } \\
\text { limbah }\end{array}$ & $\begin{array}{l}\text { Zat } \\
\text { pewarna } \\
\text { dan } \\
\text { penolong }\end{array}$ & Rarely & $\begin{array}{l}\text { Pekerja } \\
\text { membuang } \\
\text { limbah } \\
\text { sembarang }\end{array}$ & $\begin{array}{l}\text { Iritasi kulit } \\
\text { Keracunan }\end{array}$ & $\begin{array}{l}\text { Tidak tersedia } \\
\text { fasilitas pengolahan } \\
\text { limbah } \\
\text { Pekerja tidak } \\
\text { mengetahui bahaya } \\
\text { limbah batik }\end{array}$ \\
\hline
\end{tabular}


Tabel 3. Tingkat resiko pada proses produksi batik

\begin{tabular}{|c|c|c|c|c|c|}
\hline Process & $\begin{array}{l}\text { Consequence } \\
\text { (C) }\end{array}$ & $\begin{array}{l}\text { Exposure } \\
\text { (E) }\end{array}$ & $\begin{array}{l}\text { Probability } \\
\qquad(P)\end{array}$ & Rating & Risk Level \\
\hline Pembatikan & 1 & 10 & 10 & 100 & $\begin{array}{l}\text { Urgent, requires attention as soon as } \\
\text { possible }\end{array}$ \\
\hline Pewarnaan & 1 & 3 & 10 & 30 & $\begin{array}{l}\text { Hazard should be eliminated without delay, } \\
\text { but the situation is not an emergency }\end{array}$ \\
\hline Pelorodan & 1 & 3 & 10 & 30 & $\begin{array}{l}\text { Hazard should be eliminated without delay, } \\
\text { but the situation is not an emergency }\end{array}$ \\
\hline $\begin{array}{l}\text { Penanganan } \\
\text { limbah }\end{array}$ & 5 & 1 & 6 & 30 & $\begin{array}{l}\text { Hazard should be eliminated without delay, } \\
\text { but the situation is not an emergency }\end{array}$ \\
\hline
\end{tabular}

oleh Fine (1971).

Pembatikan merupakan proses memberikan malam pada sebidang kain menurut garis motif yang telah ditentukan. Pada prosesnya, pekerja akan melakukan kontak langsung dengan malam yang dicairkan di atas kompor tanpa alat pelindung diri. Anggota tubuh pekerja dapat terkena cairan malam panas ataupun kompor ketika pekerja tidak hati-hati dan fokus pada pekerjaannya. Selain itu, pekerja juga terpapar uap malam yang secara terus menerus mengenai pekerja.

Tabel 3 menunjukkan pemeringkatan terhadap resiko yang mungkin terjadi pada proses produksi batik. Pada proses pembatikan konsekuensi dari paparan hazard malam panas adalah kulit melepuh serta sesak nafas.Kensekuensi tersebut tergolong rating 1 karena tidak memerlukan penanganan medis khusus. Sedangkan pada proses pembatikan tersebut pekerja sama sekali tidak menggunakan alat pelindung diri, oleh karena itu diberikan rating 10 dan nilai probabilitas diberikan 10 karena jika hazard tersebut terjadi maka akibat berupa kulit melepuh dan sesak nafas adalah yang paling mungkin terjadi. Nilai rating diperoleh dari hasil perkalian antara consequence, exposure dan probability.

Pada tahap observing akan dilakukan pengamatan terhadap perilaku kerja yang dikategorikan kedalam perilaku aman (safe) dan tidak aman (at risk). Pada pengkategorian perilaku yang diamati akan digunakan critical

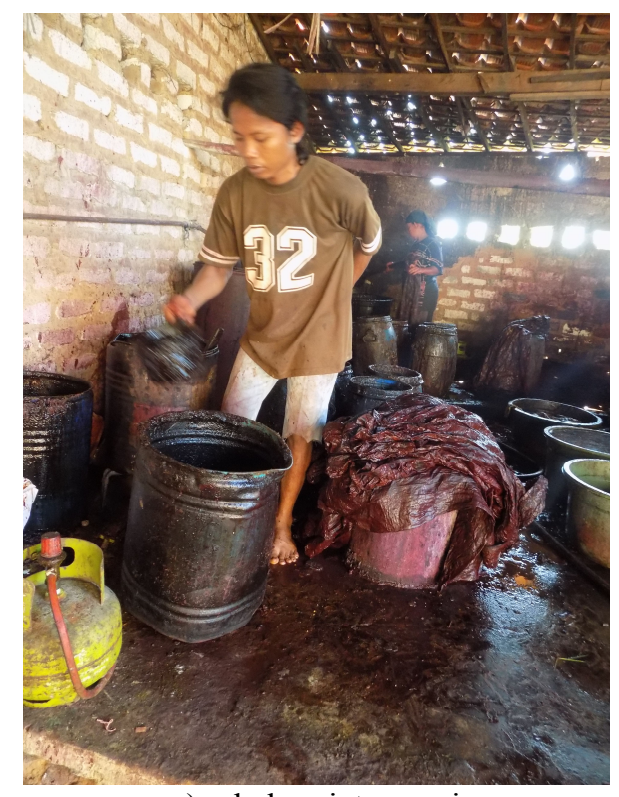

a) sebelum intervensi

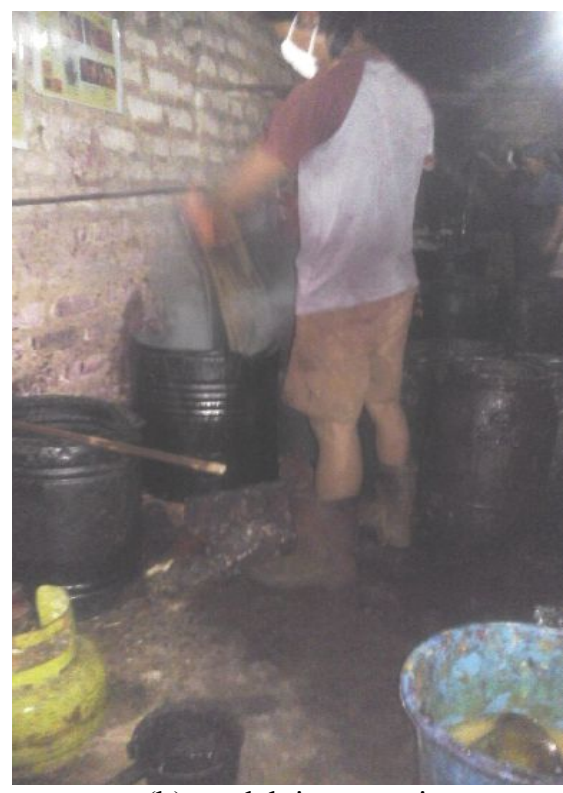

(b) setelah intervensi

Gambar 1. Program intervensi pada proses pelorodan 
Tabel 4. Nilai safe score pada proses produksi batik sebelum dan sesudah intervensi

\begin{tabular}{|c|c|c|c|c|c|c|c|}
\hline \multirow{2}{*}{ No } & \multirow{2}{*}{ Target perilaku } & \multicolumn{2}{|c|}{$\begin{array}{c}\text { Sebelum } \\
\text { intervensi }\end{array}$} & \multicolumn{2}{|c|}{$\begin{array}{c}\text { Sesudah } \\
\text { intervensi }\end{array}$} & \multicolumn{2}{|c|}{ Perubahan } \\
\hline & & Safe & At -Risk & Safe & At -Risk & Safe & At -Risk \\
\hline 1 & $\begin{array}{l}\text { Membuang limbah kedalam } \\
\text { penampung limbah }\end{array}$ & 3 & 12 & 6 & 9 & +3 & -3 \\
\hline 2 & Menangani limbah sesuai prosedur & 3 & 12 & 9 & 6 & +6 & -6 \\
\hline 3 & $\begin{array}{l}\text { Memakai alat pelindung diri masker } \\
\text { saat bekerja }\end{array}$ & 3 & 12 & 6 & 9 & +3 & -3 \\
\hline 4 & $\begin{array}{l}\text { Memakai alat pelindung diri sarung } \\
\text { tangan saat bekerja }\end{array}$ & 9 & 6 & 12 & 3 & +3 & -3 \\
\hline 5 & $\begin{array}{l}\text { Memakai alat pelindung diri sepatu } \\
\text { safety saat bekerja }\end{array}$ & 9 & 6 & 12 & 3 & +3 & -3 \\
\hline & Total & 27 & 48 & 45 & 30 & +18 & -18 \\
\hline \multicolumn{2}{|r|}{$\begin{array}{c}\% \text { safe score }=(\text { total safe observation }) / \\
(\text { total safe observation }+ \text { total at risk } \\
\text { observation }) \times 100 \%\end{array}$} & \multicolumn{2}{|c|}{$36 \%$} & \multicolumn{2}{|c|}{$60 \%$} & \multicolumn{2}{|c|}{$+24 \%$} \\
\hline
\end{tabular}

Ket* : nilai safe dan at risk pada setiap target perilaku diperoleh dari perhitungan critical behavior checklist

\section{behavior checklist.}

Indikator target perilaku yang akan diamati didasarkan dari hasil identifikasi bahaya serta evaluasi resiko pada tahap define. Enam target perilaku berupa perilaku membuang limbah pada penampung limbah, membuang limbah sesuai prosedur, selain itu dalam hal pemakaian alat pelindung diri diketahui bahwa pada identifikasi bahaya perilaku yang banyak menyebabkan bahaya adalah pada pemakaian atribut alat pelindung diri (masker, sarung tangan, dan safety shoes). Setelah target perilaku telah ditentukan maka selanjutnya dapat dilakukan pengamatan untuk mengetahui safe score sebelum dilaksanakan intervensi. Pada Tabel 4 implementasi K3 di industri batik Madura menunjukkan safe score $36 \%$ yang berarti sebanyak $64 \%$ terdapat potensi resiko yang disebabkan oleh perilaku kerja tidak aman. Hal ini senada dengan Ansori, dkk. (2015) yang menyatakan, bahwa tingkat kinerja $\mathrm{K} 3$ di industri batik tulis Madura terkategori rendah. Oleh karena itu, berdasarkan hasil temuan tersebut diperlukan intervensi untuk mengurangi potensi resiko akibat perilaku tidak aman pekerja.

Intervensi dilakukan dengan menyusun program-program berdasarkan hasil pada tahap define. Program intervensi yang dilakukan meliputi pengadaan alat pelindung diri, perbaikan lingkungan kerja (pencahayaan dan tata letak fasilitas), poster dan bak filtrasi. Salah satu program intervensi ditunjukkan pada Gambar 1 dimana perilaku pekerja dalam pemakaian alat pelindung diri dari sebelum intervensi pekerja tidak memakai alat pelindung diri menjadi memakai masker, sarung tangan, dan juga sepatu safety pada saat bekerja.

Pada tahap akhir dari pendekatan BBS adalah melakukan pengujian (testing) terhadap program intervensi. Pengujian dilakukan dengan menghitung safe score sebagaimana dilakukan pada tahap observing yang ditunjukkan pada Tabel 4.

Sebelum program intervensi dijalankan, maka terlebih dahulu dilakukan sosialisasi programprogram intervensi kepada seluruh pekerja dan pemilik usaha batik. Tujuan sosialisasi adalah untuk memberikan pengetahuan dan menanamkan kesadaran pada pekerja dan pemilik tentang potensi bahaya yang mengancam di tempat kerja yang diakibatkan oleh faktor perilaku. Tahap pengujian dilakukan selama 1 bulan di salah satu UKM Batik Madura dengan melibatkan semua pekerja dan pemilik usaha. Berdasarkan hasil pengamatan diperoleh peningkatan masing-masing nilai safe dan sebaliknya terjadi penurunan pada nilai at risk pada setiap target perilaku.

Dengan kondisi demikian maka nilai safe score secara keseluruhan mengalami peningkatan menjadi $60 \%$ yang mengindikasikan bahwa program intervensi yang dilakukan memberikan pengaruh terhadap peningkatan perilaku aman pekerja batik yaitu dengan menurunkan potensi 
resiko kecelakaan kerja sebesar $24 \%$. Hasil ini diperkuat dengan Ningsih dan Ardyanto (2013) bahwa intervensi yang dilakukan melalui program STOP dapat meningkatkan perilaku aman pekerja.

\section{SIMPULAN}

Kajian terhadap implementasi K3 di industri batik Madura memerlukan suatu upaya yang serius. Pengamatan yang dilakukan pada proses produksi batik memperlihatkan suatu kondisi kerja dengan tingkat resiko bahaya cukup tinggi. Karena proses produksi batik menggunakan peralatan sederhana dan manual, sehingga keterlibatan faktor manusia menjadi dominan maka kajian ini melihat dari perspektif perilaku pekerja.

Dengan mengaplikasikan pendekatan Behavior Based Safety mengindikasikan bahwa program-program intervensi K3 yang telah disusun mampu memberikan peningkatan skor perilaku aman pekerja atau dengan kata lain mampu mengurangi potensi resiko bahaya akibat perilaku tidak aman.

Kesadaran pekerja untuk berperilaku aman saat bekerja diindikasikan oleh pemahaman prosedur dan penggunaan alat pelindung diri yang ditunjukkan dengan tingkat konsistensi pemakaian cukup tinggi. Pekerja juga memahami prosedur penanganan limbah batik secara benar, sehingga tidak ada perilaku pekerja lagi yang membuang limbah sembarangan. Meskipun demikian masih terdapat beberapa target perilaku yang belum mencapai sasaran, sehingga memerlukan komitmen dari pekerja dan pemilik usaha untuk secara konsisten berperilaku aman.

\section{DAFTAR PUSTAKA}

Al-Hemoud, A.M.; Al-Asfoor, M.M. 2006. "A behavior based safety approach at a Kuwait research institution". Journal of Safety Research. Vol. 37 (2), pp. 201-206.

Ansori, N.; Novianti, T.; Agustina, F.; Rachmawati, N. 2015. "Safety performance index pada industri batik tulis berdasarkan kriteria majemuk". Jurnal Teknik Industri, Vol 17 (2), pp. $105-110$.

Fine, W.T. 1971. Mathematical Evaluations for Controlling Hazards. Maryland: Naval Ordnance Laboratory.

Dula, C.S.; Geller, E. S. 2007. Creating a Total Safety Traffic Culture. Virginia, USA: AAA Foundation for Traffic Safety

Ningsih, A.R.; Ardyanto, Y.W. 2013. "Evaluasi pelaksanaan behavior based safety pada program STOP dalam membentuk perilaku aman tenaga kerja di PT X tahun
2013”. The Indonesian Journal of Occupational Safety and Health, Vol. 2 (1), pp. $35-44$.

Wayne, D.M.2004. An Analysis of the Behavior-Based Safety Program at Company XYZ. University of Winconsin Stout

Wignjosoebroto, S. 2012. "Pendekatan perilaku manusia untuk mencegah kenaikan tingkat kecelakaan kerja di industry batik. Prosiding Seminar Nasional Ergonomi: Peran Ergonomi dalam Industri Kreatif di Indonesia. Bandung, Indonesia.

Williams, J.H.; Geller, E.S. 2000. "Behavior-based intervention for occupational safety: critical impact of social comparison feedback". Journal of Safety Research, Vol. 31 (3), pp. 135 - 142.

Xiongjun, Y.; Kaiqan, W. 2012. "Study on safety management of small and medium-sized enterprises based on BBS". International Symposium on Safety Science and Technology. Procedia Engineering, Vol. 45 , pp. 208-213. 